\title{
Analisa Perbandingan Performa Openstack dan Apache Cloudstack dalam Model Cloud Computing Berbasis Infrastructure As a Service
}

\author{
Hari Triyanto $^{\# 1}$, Arif Bijaksana Putra Negara ${ }^{\# 2}$, Muhammad Azhar Irwansyah" ${ }^{\# 3}$

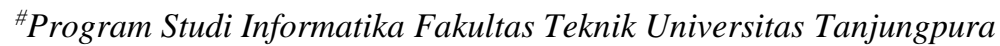 \\ Jl. Prof. Dr. H. Hadari Nawawi, Kota Pontianak, 78115 \\ 'hari.triyanto22@gmail.com \\ 2arifbpn@gmail.com \\ ${ }^{3}$ irwansyah.azhar@gmail.com
}

\begin{abstract}
Abstrak - Efisiensi pemanfaatan sumber daya komputasi dapat di lakukan dengan melakukan virtualisasi pada mesin fisik komputer. Pada cloud computing, sumber daya seperti CPU, memori, storage dan jaringan dapat dipandang sebagai suatu layanan dengan virtualisasi sebagai jantungnya. Openstack dan Cloudstack merupakan salah satu opensource untuk membangun cloud computing dengan model IaaS. Penelitian ini bertujuan untuk membandingkan Openstack dan Cloudstack dalam perancangan private cloud computing dengan aspek pengujian web server, komputasi, oltp database dan jaringan. Pengujian menggunakan metrik skalabilitas dengan metode pengujian overhead dan linearity. Implementasi dilakukan pada satu server dengan menggunakan satu router dan satu laptop sebagai client. Client bertugas untuk menjalankan pengujian menggunakan tools seperti Httperf, Sysbench dan Iperf. Sejumlah beban pengujian diberikan untuk tiap tiap instance berdasarkan skenario pengujian yang telah di buat. Hasil pengujian menunjukan bahwa waktu eksekusi yang diperlukan untuk mengakses web server dan komputasi pada instance Openstack lebih rendah daripada instance Cloudstack. Sedangkan pada pengujian oltp database dan jaringan, hasil pengujian menunjukan bahwa instance pada Cloudstack lebih unggul dengan waktu eksekusi oltp database yang lebih rendah, throughput yang lebih tinggi serta jitter yang lebih rendah. Oleh karena itu, Openstack unggul dalam penggunaan aplikasi berbasis web dan komputasi sedangkan Cloudstack unggul dalam aplikasi dengan transaksi database yang tinggi serta membutuhkan jaringan yang baik.
\end{abstract}

Kata kunci- IaaS, Openstack, Cloudstack, Cloud Computing, Studi Komparatif

\section{Pendahuluan}

Perkembangan komputasi telah beralih dari komputasi tradisional ke arah komputasi awan. Komputasi awan (cloud computing) adalah sebuah model komputasi baru yang membawa disiplin, teknologi dan model bisnis untuk menyajikan informasi teknologi sesuai permintaan. Cloud computing merupakan perkembangan dari komputasi tradisional. Pada komputasi tradisional, seluruh sumber daya seperti CPU, memori, penyimpanan dan jaringan digabung menjadi satu untuk menghasilkan daya komputasi yang besar. Sedangkan pada cloud computing, sumber daya yang besar tersebut dipecah menjadi beberapa mesin virtual agar penggunaannya lebih efisien.

Pada cloud computing terdapat model pengembangan public cloud dan private cloud. Public cloud memberikan kemudahan pada pengguna, organisai ataupun perusahaan untuk mengeluarkan biaya sesuai dengan sumber daya yang digunakan serta terbebas dari biaya perancangan infrastruktur. Pengguna tersebut dapat mengatur jumlah pembiayaan yang dikeluarkan agar proses bisnis tetap berjalan. Akan tetapi semakin berkembangnya kebutuhan dari pengguna maka diperlukan sumber daya yang lebih besar pula. Selain itu, permasalahan seperti keamanan data, kontrol dan perawatan menjadi salah satu poin yang diperhitungkan dalam menggunakan public cloud. Penggunaan private cloud merupakan salah satu solusi dalam menjaga keamanan data vital pengguna. Selain itu, model private cloud memungkinkan pengguna untuk melacak permasalahan dalam menjalankan sistem.

Dalam perancangan private cloud terdapat beberapa perangkat lunak opensource yang dapat digunakan untuk perancangan private cloud seperti Eucalyptus, Opennebula, Openstack dan Cloudstack. Perangkat lunak tersebut melakukan manajemen terhadap pengelolaan CPU, memori, penyimpanan dan jaringan. Openstack dan Apache Cloudstack merupakan perangkat lunak yang dapat digunakan untuk membangun private cloud computing berbasis IaaS. Openstack dan Apache Cloudstack digunakan oleh organisasi, perusahaan, pemerintah dan akademisi. Openstack dan Apache Cloudstack dapat digunakan pada sistem operasi Ubuntu, Centos, Redhat serta berbagai hypervisor seperti KVM dan Xen sebagai jantung virtualisasinya. Ubuntu memiliki dukungan komunitas yang besar sehingga memudahkan 
pengguna dalam melakukan konfigurasi. Dalam virtualisasi menggunakan hypervisor, Xen dianggap sebagai hypervisor yang lebih stabil pada I/O dan jaringan sedangkan KVM unggul pada daya komputasinya.

Kemunculan opensource cloud computing yang berbeda memerlukan keputusan untuk memilih perangkat lunak cloud computing yang paling cocok dengan kebutuhan pengguna. Perbedaan komponen dan arsiktektur perangkat lunak cloud computing mengakibatkan perbedaan performa pada CPU, memori, R/W hard disk dan QoS jaringan yang diberikan. Diperlukan suatu analisa untuk mengetahui perbandingan performa cloud computing yang digunakan. Analisa dilakukan menggunakan metrik skalabilitas dengan metode overhead dan linearity untuk mengukur performa sesuai dengan aspek yang akan diuji. Diharapkan dengan adanya analisa perbandingan performa tersebut dapat membantu pengguna dalam pemilihan perangkat lunak berbasis IaaS.

\section{URAIAN PENELITIAN}

\section{A. Cloud Computing}

Cloud computing adalah sebuah client-server dimana resource seperti server, storage, network dan software dapat dipandang sebagai layanan yang dapat diakses oleh pengguna secara remote dan setiap saat [1]. Pengguna dapat menikmati berbagai layanan yang disediakan oleh provider cloud computing tanpa perlu terlalu banyak meminta bantuan teknis atau support dari pihak provider

Komputasi awan atau cloud computing adalah teknologi yang cukup baru di dalam dunia IT (Information Technology) di mana komputasi awan ini berfungsi sebagai layanan berupa (jaringan, server, aplikasi, penyimpanan dan lain-lain) yang disediakan kepada para pengguna internet untuk kemudahan dalam beraktifitas [2]. Ada tiga jenis bentuk layanan cloud computing yang diberikan kepada pengguna. Layanan tersebut sebagai berikut:

1) Software as a Service: Software as a Service atau SaaS merupakan Layanan yang diberikan dengan menyediakan software maupun aplikasi yang dapat diakses pelanggan via internet [3]. Penyedia layanan cloud computing berinteraksi dengan pengguna dan pelanggan melalui sebuah front-end panel. SaaS menghapus kebutuhan organisasi untuk melakukan instalasi dan menjalankan aplikasi pada komputer atau data center mereka. Pengguna dapat menggunakan aplikasi tanpa harus mengerti bagaimana data disimpan, melakukan perawatan dan pengembangan aplikasi tersebut

2) Platform as a Service: Platform as a Service atau PaaS merupakan layanan perangkat lunak perantara pada lingkungan cloud untuk memfasilitasi berjalannya program aplikasi aplikasi lainnya [4]. PaaS menjadi wadah bagi pengguna untuk menjalankan aplikasinya. Pada PaaS, penyediaan platform bagi developer yang dikelola oleh pihak provider dan diakses melalui internet. PaaS memungkinkan kita untuk membangun aplikasi, upload aplikasi, melakukan testing aplikasi, ataupun mengatur konfigurasi yang dibutuhkan dalam proses pengembangan aplikasi. Pengguna hanya perlu fokus pada pengembangan aplikasi karena perawatan sistem dikelola oleh pihak provider.

3) Infrastructure as a Service: Infrastructure as a Service atau IaaS adalah salah satu dari layanan dasar dari cloud computing yang menyediakan layanan berupa infrastruktur IT seperti CPU, storage, memory, network, dan sebagainya yang bersifat scalable dimana sumber daya yang disewakan dapat diubah ubah sesuai kebutuhan pelanggan dengan mudah [5]. IaaS menyediakan sumber daya komputer yang tervirtualisasi dan dapat diakses melalui internet. Sumber daya tersebut dipesan oleh pengguna sesuai dengan kebutuhan dan biaya yang dimiliki oleh pengguna. Pengguna dapat memilih sistem dengan berbagai varian cpu, memori dan penyimpanan. Selain itu pengguna juga dapat melakukan konfigurasi jaringan meskipun bersifat terbatas pada kebijakan provider. IaaS memungkinkan pengguna dalam memilih dan mengkonfigurasikan sistem operasi yang disediakan oleh provider. Pengguna dapat mengakses terminal dan melakukan instalasi package untuk mendukung pengembangan aplikasi.

\section{B. Openstack}

OpenStack merupakan open source cloud computing software untuk membangun infrastruktur cloud yang dapat diandalkan [5].

1) Keystone: Keystone (Identity Service) menyediakan layanan identitas dan akses kebijakan untuk semua komponen dalam keluarga OpenStack [6]. Keystone menyediakan otentikasi dan otorisasi untuk semua komponen OpenStack. Otorisasi akan memverifikasi apakah pengguna yang terotentikasi memiliki akses ke layanannya yang dia minta atau tidak.

2) Glance: Glance (Image Service) OpenStack Imaging Service adalah salah satu produk dari OpenStack yang digunakan untuk layanan virtual disk images [6].

3) Nova: Nova (Compute Service) bertindak sebagai platform management yang mengelola sumber daya komputasi, jaringan, otorisasi, dan kebutuhan skalabilitas dari OpenStack cloud [6]. Nova menangani seluruh kegiatan yang berkaitan dengan siklus hidup instance.

4) Neutron: Neutron (Networking Service) adalah salah satu komponen Openstack yang menyediakan layanan cloud Network as a Service dan memungkinkan pengguna untuk melakukan konfigurasi jaringan pada cloud [6]. Neutron memungkinkan pengguna untuk menghubungkan perangkat antarmuka yang dikelola oleh Openstack ke perangkat lainnya. Neutron berinteraksi dengan Nova untuk menyediakan jaringan dan konektivitas dengan instance.

5) Horizon: Horizon (User Interface Service) merupakan suatu layanan user interface dalam infrastruktur Openstack yang memberikan akses visualisasi bagi user dalam menciptakan cloud [6]. Horizon menyediakan suatu layanan administrator dengan 
sebuah GUI untuk mengakses instance, melakukan provisioning dan otomatisasi sumber daya cloud.

6) Cinder: Cinder (Block Storage Service) adalah komponen penyimpanan blok yang lebih analog dengan gagasan tradisional komputer yang dapat mengakses lokasi tertentu pada disk drive serta menyediakan perangkat penyimpanan untuk digunakan dengan instances pada OpenStack [6].

\section{Apache Cloudstack}

Apache Cloudstack merupakan suatu perangkat lunak opensource yang digunakan untuk membangun private, public atau hybrid cloud IaaS dengan mengelola sumber daya komputer [7]. Cloudstack dikembangkan dan didukung oleh komunitas dan beberapa provider cloud saat ini. Sebagai salah satu perangkat lunak IAAS, Cloudstack didukung Apache Software Foundation (ASF) sebagai projek utamanya di tahun 2013.

1) Host: Host merupakan suatu komputer yang menyediakan daya komputasi untuk menjalankan virtual machine. Host pada Cloudstack menggunakan hypervisor seperti Xen Server dan KVM untuk mengelola virtual machine. Host merupakan zona terkecil dalam pengembangan cloud computing menggunakan Cloudstack.

2) Cluster: Cluster merupakan kumpulan dari beberapa host. Satu cluster terdiri dari beberapa perangkat yang identik dan menjalankan hypervisor yang sama, di satu subnet yang sama dan saling berbagi media penyimpanan. Setiap VM yang berjalan di satu cluster dapat bermigrasi antar host tanpa mengganggu layanan pengguna.

3) Pods: Pods merupakan satu kumpulan cluster dalam 1 rak. Tiap-tiap host di pod yang sama menggunakan subnet jaringan yang sama.

4) Zone: Zone memiliki kedudukan terbesar kedua dalam perancangan cloud computing menggunakan Cloudstack. Zone terdiri dari sebuah pod atau lebih dan dimungkinkan untuk memiliki penyimpanan redundan. Suatu zone dapat dianggap sebagai sebuah datacenter.

\section{Httperf}

Httperf adalah program untuk mengukur kinerja atau performansi dari web server yang dibuat oleh David Mosberger dari HP Labs [8]. Httperf menyediakan fitur yang fleksibel dalam pembuatan beban kerja sesuai dengan variable yang diberikan padanya

\section{E. Sysbench}

Sysbench adalah aplikasi benchmark yang ditujukan untuk mengukur performansi dari suatu database yang dijalankan melalui command prompt atau terminal pada sistem operasi linux [9]. Sysbench dapat melakukan tes pada CPU dan database. Pengujian yang dilakukan pada tes CPU berupa mencari bilangan prima dalam jumlah yang telah ditentukan. Sysbench akan menverifikasi suatu bilangan prima dengan membagi bilangan tersebut dengan rentang angka dua hingga akar dari bilangan tersebut.
Pengujian yang dilakukan pada tes database dilakukan dengan melakukan insert, read, update dan delete pada database.

\section{F. Iperf}

Iperf adalah perintah yang digunakan untuk mengukur kinerja bandwidth TCP dan UDP untuk menampilkan throughput, delay jitter, dan packet loss [10]. Iperf dapat digunakan untuk mengukur performa jaringan atau koneksi baik antar instance maupun instance ke luar melalui terminal.

\section{G. Metodologi Penelitian}

Diagram alir (flowchart) penelitian yang digunakan untuk menjelaskan langkah-langkah perencanaan dalam melakukan penelitian. Diagram alir (flowchart) yang digunakan pada penelitian ini dapat dilihat pada Gambar 1.
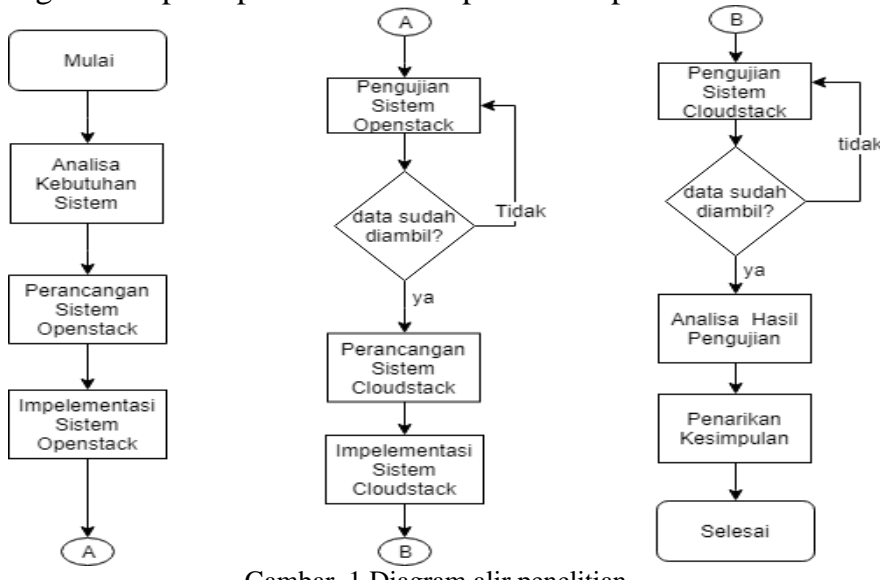

Gambar. 1 Diagram alir penelitian

\section{H. Rancang Arsitektur Jaringan}

Arsitektur jaringan yang digunakan dalam penelitian ini dapat dilihat pada Gambar 2.

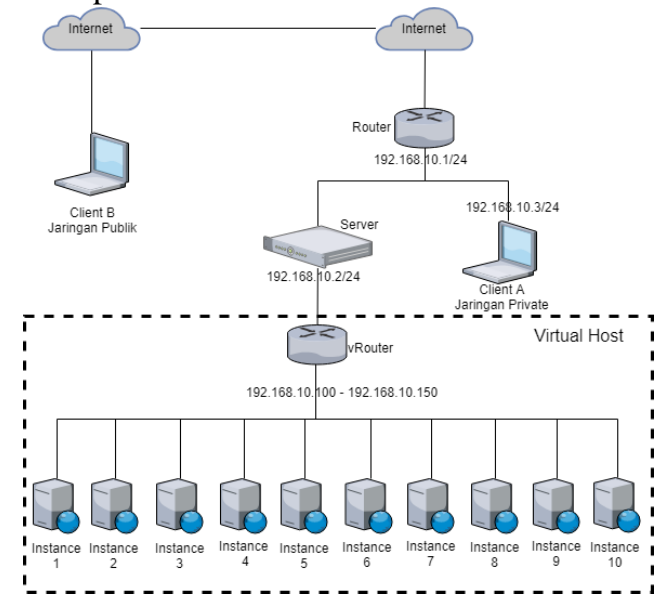

Gambar. 2 Arsitektur jaringan

\section{Rancang Pengujian Overhead}

Overhead pada virtualisasi server adalah seberapa sering dan lamanya waktu yang dibutuhkan oleh hypervisor untuk menyelesaikan suatu proses dan menjalankan kembali virtual machine [11]. Pengujian 
overhead dilakukan dengan cara menambahkan instance dan melakukan pengujian pada instance tersebut. Setiap instance yang di tambahkan akan di uji secara bertahap. Aspek yang diuji pada instance tersebut yaitu kecepatan komputasi, web server, database dan kualitas jaringan. Pengujian dijalankan oleh client yang terhubung ke instance yang di uji. Simulasi pengujian overhead dapat dilihat pada Gambar 3.

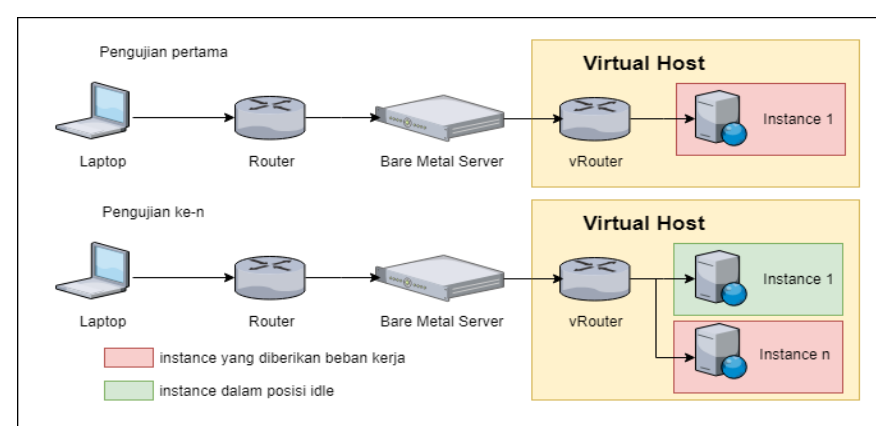

Gambar. 3 Skenario pengujian overhead

\section{J. Rancang Pengujian Linearity}

Linearitas pada virtualisasi server dapat diartikan sama dengan overhead, akan tetapi dalam pengujian linearitas, virtual machine yang ditambahkan diberikan aplikasi yang sama [11]. Pengujian linearitas mengarah pada penilaian kuantitatif tetang waktu yang diperlukan oleh suatu sistem untuk memproses beban kerja sesuai dengan jumlah mesin virtual yang digunakan. Pengujian linearitas dilakukan dengan cara memberikan beban kerja untuk setiap instance yang ditambahkan. Aspek yang diuji pada linearitas yaitu waktu eksekusi perintah pada web server, komputasi, database dan jaringan. Setiap pengujian dilakukan bersamaan untuk setiap mesin virtual yang dijalankan.

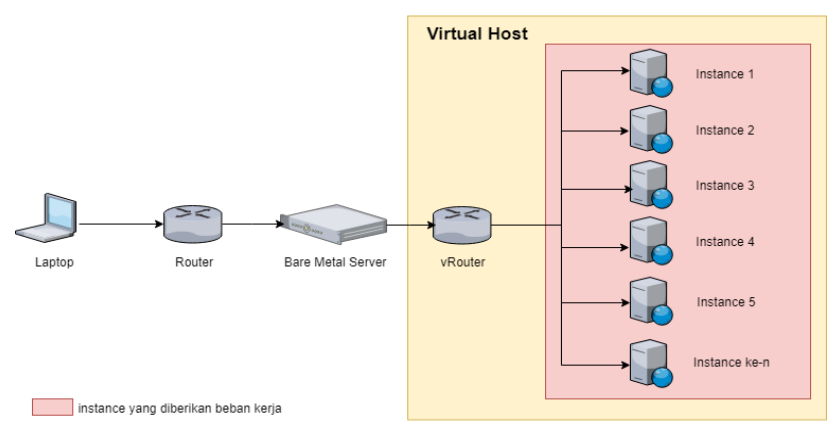

Gambar. 4 Skenario pengujian linearity

\section{HASIL DAN PEMBAHASAN}

\section{A. Hasil dan Analisa Webserver}

Webserver adalah sebuah bentuk server yang khusus digunakan untuk menyimpan halaman website atau homepage [12]. Pengujian webserver menggunakan Httperf untuk mendapatkan waktu eksekusi dengan jumlah koneksi sebanyak dua puluh ribu koneksi. Adapun pengujian dilakukan dengan pada localhost instance dengan web awal pada saat pertama kali dilakukan instalasi Apache webserver. Hasil pengujian overhead webserver dapat dilihat pada Tabel 1.

TABEL I

Hasil PENGUJIAN OVERHEAD WEBSERVER

\begin{tabular}{|c|c|c|c|}
\hline Instance ke & $\begin{array}{c}\text { Openstack } \\
\text { (detik) }\end{array}$ & $\begin{array}{c}\text { Cloudstack } \\
\text { (detik) }\end{array}$ & $\begin{array}{c}\text { Host } \\
\text { (detik) }\end{array}$ \\
\hline 1 & 8.136 & 8.4986 & 3.2256 \\
\hline 2 & 8.4672 & 8.6648 & 3.2256 \\
\hline 3 & 8.8068 & 8.7632 & 3.2256 \\
\hline 4 & 8.8868 & 8.8048 & 3.2256 \\
\hline 5 & 9.0304 & 8.9424 & 3.2256 \\
\hline 6 & 9.3322 & 9.2532 & 3.2256 \\
\hline 7 & 9.4234 & 9.5312 & 3.2256 \\
\hline 8 & 9.4598 & 10.8376 & 3.2256 \\
\hline 9 & 9.8056 & 9.767 & 3.2256 \\
\hline 10 & 9.5902 & 10.7682 & 3.2256 \\
\hline
\end{tabular}

Berdasarkan hasil pengujian pada Tabel 1, dibuatlah grafik untuk menampilkan hasil perbandingan performa Openstack dan Cloudstack dalam bentuk visual pada Gambar 5.

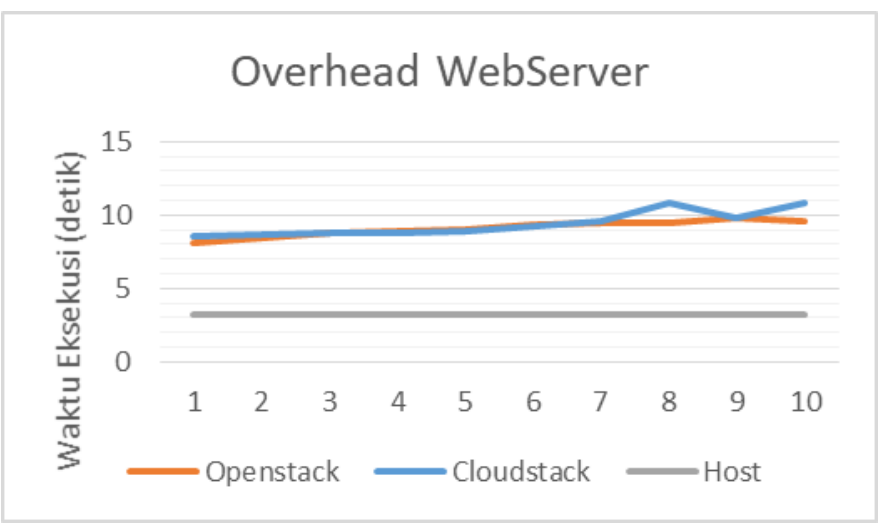

Gambar. 5 Grafik pengujian overhead webserver

Pada pengujian linearity, seluruh instance yang sedang aktif menjalankan httperf secara bersamaan. Hasil dari pengujian linearity web server dapat dilihat pada Tabel 2 berikut.

TABEL II

HASIL PENGUJIAN LINEARITY WEBSERVER

\begin{tabular}{|c|c|c|}
\hline Instance ke & $\begin{array}{c}\text { Openstack } \\
\text { (detik) }\end{array}$ & $\begin{array}{c}\text { Cloudstack } \\
\text { (detik) }\end{array}$ \\
\hline 1 & 8.4528 & 8.4986 \\
\hline 2 & 9.0643 & 8.611 \\
\hline 3 & 7.3717 & 9.7761 \\
\hline 4 & 8.9705 & 9.9766 \\
\hline 5 & 9.2102 & 10.2115 \\
\hline 6 & 8.3576 & 10.6006 \\
\hline 7 & 7.6143 & 8.954 \\
\hline 8 & 9.1757 & 9.5712 \\
\hline 9 & 8.7316 & 12.5537 \\
\hline 10 & 8.8121 & 13.2984 \\
\hline
\end{tabular}

Berdasarkan hasil pengujian pada Tabel 2, dibuatlah grafik untuk menampilkan hasil perbandingan performa Openstack dan Cloudstack dalam bentuk visual pada Gambar 6. 


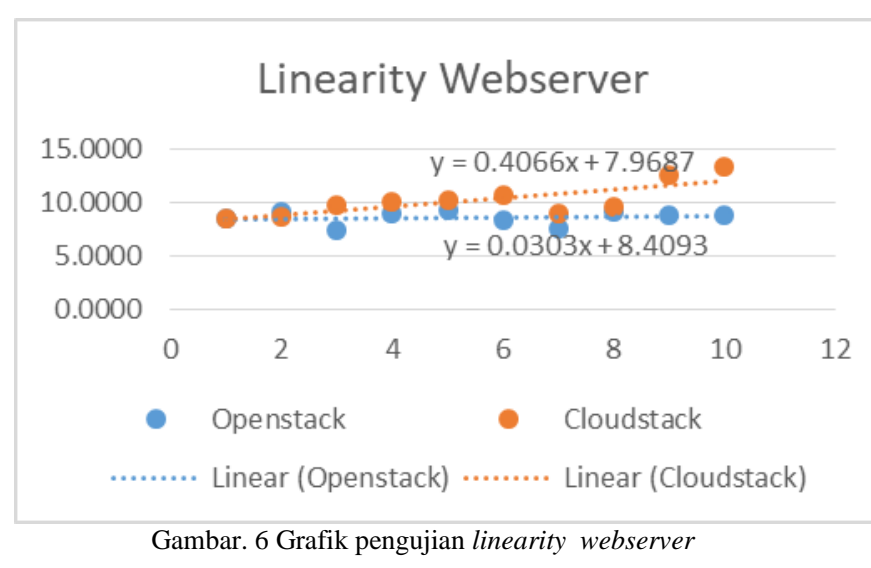

Pengujian httperf berfokus pada waktu eksekusi yang diperlukan oleh instance untuk melakukan connection, request dan reply. Httperf menggunakan kemampuan CPU untuk membuat permintaan tersebut. Tujuan dari pengujian ini adalah untuk mendapatkan waktu eksekusi yang lebih rendah antara instance Openstack dan Cloudstack dengan host sebagai media pembandingnya. Dengan waktu eksekusi yang lebih rendah maka lebih banyak permintaan http yang dapat dibuat per detik oleh web server tersebut.

Berdasarkan pengujian overhead web server yang dilakukan pada Openstack dan Cloudstack, didapatkan hasil bahwa waktu eksekusi yang diperlukan instance cenderung naik seiring dengan bertambahnya jumlah instance dijalankan. Kenaikan tersebut dapaat kita perhatikan pada Gambar 5. Hasil pengujian menunjukan bahwa waktu eksekusi antara Cloudstack dan Openstack relatif sama pada instance pertama hingga instance ketujuh. Namun pada instance delapan hingga sepuluh Openstack memiliki waktu eksekusi yang lebih rendah daripada Cloudstack. Jika dibandingkan dengan host, waktu eksekusi pada Openstack dan Cloudstack lebih dari dua kali lipat untuk pengujian tiap tiap instance. Waktu eksekusi web server pada host memang lebih baik, namun jika salah satu web pada host tersebut menggunakan seluruh sumber daya maka aka berdampak pada kinerja web yang lain. Pada instance Openstack dan Cloudstack, seluruh sumber daya tersebut terpisah, sehingga apabila salah satu instance mengalami kegagalan, maka instance lain masih dapat bekerja dnegan baik.

Berdasarkan pengujian linearity web server yang dilakukan pada Openstack dan Cloudstack, didapatkan hasil bahwa instance pada Cloudstack mengalami penambahan waktu eksekusi sebanding dengan jumlah instance yang digunakan sedangkan instance pada Openstack cenderung relatif sama untuk rata rata waktu eksekusinya. Kenaikan waktu eksekusi tersebut dapat dilihat pada grafik pada Gambar 6. Pada pengujian linearity web server dapat diambil kesimpulan bahwa Openstack lebih unggul dari Cloudstack karena waktu eksekusi yang lebih relatif lebih rendah.

\section{B. Hasil dan Analisa Komputasi}

Pengujian Komputasi menggunakan Sysbench untuk menghitung waktu yang diperlukan oleh instance untuk menemukan dua puluh ribu bilangan prima. Hasil pengujian komputasi dapat dilihat pada Tabel 3 berikut.

TABEL III

HASIL PENGUJIAN OVERHEAD WEBSERVER

\begin{tabular}{|c|c|c|c|}
\hline $\begin{array}{c}\text { Instance } \\
\text { ke }\end{array}$ & $\begin{array}{c}\text { Openstack } \\
\text { (detik) }\end{array}$ & $\begin{array}{c}\text { Cloudstack } \\
\text { (detik) }\end{array}$ & $\begin{array}{c}\text { Host } \\
\text { (detik) }\end{array}$ \\
\hline 1 & 29.81958 & 31.3641 & 27.58122 \\
\hline 2 & 29.83824 & 32.02746 & 27.58122 \\
\hline 3 & 30.47266 & 32.82794 & 27.58122 \\
\hline 4 & 30.87008 & 32.92118 & 27.58122 \\
\hline 5 & 31.19182 & 33.6778 & 27.58122 \\
\hline 6 & 31.79386 & 34.05862 & 27.58122 \\
\hline 7 & 32.22864 & 35.01746 & 27.58122 \\
\hline 8 & 32.35438 & 35.17498 & 27.58122 \\
\hline 9 & 32.93492 & 35.06258 & 27.58122 \\
\hline 10 & 33.6388 & 35.71812 & 27.58122 \\
\hline
\end{tabular}

Berdasarkan hasil pengujian pada Tabel III, dibuatlah grafik untuk menampilkan hasil perbandingan performa Openstack dan Cloudstack pada Gambar 7.

\section{OVERHEAD KOMPUTASI}

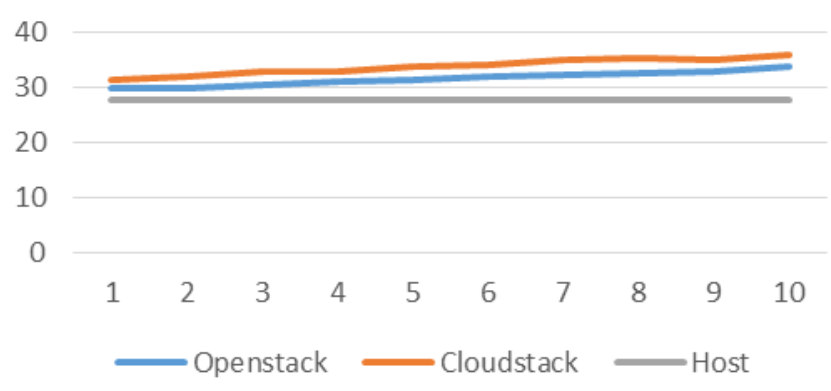

Gambar. 7 Grafik pengujian overhead komputasi

Hasil pengujian linearity komputasi dapat dilihat pada Tabel IV. Pada tabel tersebut, seluruh instance menjalankan Sysbench secara bersamaan untuk mencari dua puluh ribu bilangan prima.

TABEL IV

HASIL PENGUJIAN LINEARITY WEBSERVER

\begin{tabular}{|c|c|c|}
\hline Instance ke & $\begin{array}{c}\text { Openstack } \\
\text { (detik) }\end{array}$ & $\begin{array}{c}\text { Cloudstack } \\
\text { (detik) }\end{array}$ \\
\hline 1 & 29.4861 & 31.3641 \\
\hline 2 & 30.1301 & 31.9734 \\
\hline 3 & 30.3317 & 31.8808 \\
\hline 4 & 30.2267 & 31.4976 \\
\hline 5 & 30.8826 & 32.1455 \\
\hline 6 & 31.2808 & 32.6480 \\
\hline 7 & 30.9684 & 32.6050 \\
\hline 8 & 30.8422 & 32.5666 \\
\hline 9 & 32.9786 & 34.6349 \\
\hline 10 & 34.9860 & 36.1353 \\
\hline
\end{tabular}

Berdasarkan hasil pengujian pada Tabel IV, dibuatlah grafik untuk menampilkan hasil perbandingan performa Openstack dan Cloudstack pada Gambar 8. 


\section{LINEARITY KOMPUTASI}

40

20

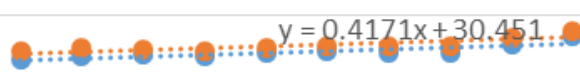

0

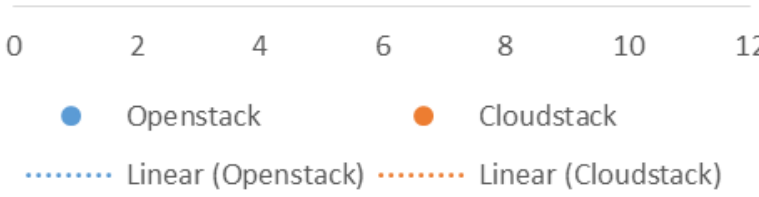

Gambar 8 Grafik pengujian linearity komputasi

Pengujian komputasi bertujuan untuk mengetahui waktu eksekusi yang dibutuhkan untuk menyelesaikan suatu perhitungan antara instance Openstack dan Cloudstack. Beberapa aplikasi berbasis web dan dekstop memerlukan CPU untuk menyelesaikan algoritma pemrogramannya. Selain itu, service lain yang bertugas untuk menjalankan sistem operasi juga bergantung pada kinerja CPU tersebut. Dengan kinerja CPU yang lebih baik maka pemrosesan layanan lain seperti ftp, web service dan perhitungan komplek menjadi lebih baik.

Berdasarkan hasil pengujian overhead komputasi yang dilakukan pada Openstack dan Cloudstack, waktu eksekusi mengalami kenaikan yang stabil sesuai dengan penambahan jumlah instance yang dijalankan. Pada pengujian ini terlihat bahwa instance pada Openstack relatif lebih baik daripada instance pada Cloudstack. Hal ini dikarenakan waktu eksekusi Openstack yang lebih rendah dibandingkan dengan Cloudstack. Waktu eksekusi tersebut dapat dilihat pada Gambar 7 yang menunjukan grafik pengujian. Pada pengujian ini, waktu eksekusi antara instance Openstack dan Cloudstack relatif mendekati waktu eksekusi host. Hal ini dikarenakan pengujian CPU pada Sysbench hanya menjalankan satu thread pengujian sehingga CPU yang bekerja antara host, Openstack dan Cloudstack sama sama berjumlah 1 core CPU.

Berdasarkan pengujian linearity komputasi yang dilakukan pada Openstack dan Cloudstack, didapatkan hasil bahwa instance pada Cloudstack mengalami penambahan waktu eksekusi sebanding dengan jumlah instance yang digunakan sedangkan instance pada Openstack cenderung relatif sama untuk rata rata waktu eksekusinya. Kenaikan waktu eksekusi tersebut dapat dilihat pada grafik pada Gambar 8. Pada pengujian linearity komputasi dapat diambil kesimpulan bahwa Openstack lebih unggul dari Cloudstack karena waktu eksekusi yang lebih relatif lebih rendah.

\section{Hasil dan Analisa Database}

Pengujian database menggunakan Sysbench untuk menghitung waktu yang diperlukan oleh instance untuk melakukan pengujian OLTP dengan jumlah data dibaca sebanyak dua puluh ribu data. OLTP adalah kelas sistem informasi yang memfasilitasi dan mengelola aplikasi berorientasi transaksi, biasanya untuk pemrosesan data entry dan retrieval [13]. Hasil pengujian komputasi dapat dilihat pada Tabel V berikut.

TABEL V

Hasil PENGUJian Overhead Database

\begin{tabular}{|c|c|c|c|}
\hline Instance ke & $\begin{array}{c}\text { Openstack } \\
\text { (detik) }\end{array}$ & $\begin{array}{c}\text { Cloudstack } \\
\text { (detik) }\end{array}$ & $\begin{array}{c}\text { Host } \\
\text { (detik) }\end{array}$ \\
\hline 1 & 158.29834 & 129.28872 & 62.22126 \\
\hline 2 & 161.04316 & 129.61084 & 62.22126 \\
\hline 3 & 161.42964 & 129.69062 & 62.22126 \\
\hline 4 & 164.13384 & 131.01852 & 62.22126 \\
\hline 5 & 163.05474 & 130.70722 & 62.22126 \\
\hline 6 & 164.30342 & 134.70512 & 62.22126 \\
\hline 7 & 162.08348 & 134.29838 & 62.22126 \\
\hline 8 & 160.37508 & 135.6868 & 62.22126 \\
\hline 9 & 156.2803 & 138.5282 & 62.22126 \\
\hline 10 & 156.88988 & 145.6028 & 62.22126 \\
\hline
\end{tabular}

Berdasarkan hasil pengujian pada Tabel V, dibuatlah grafik untuk menampilkan hasil perbandingan performa Openstack dan Cloudstack dalam bentuk visual pada Gambar 9.

\section{Overhead Database}

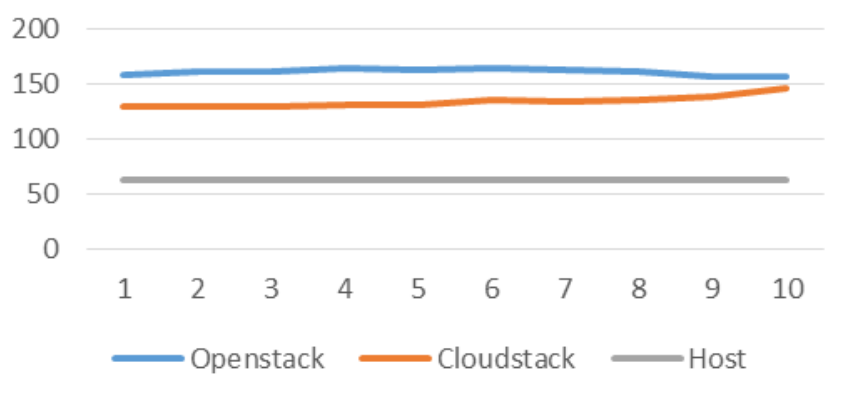

Gambar. 9 Grafik pengujian overhead database

Pengujian linearity database menggunakan Sysbench untuk melakukan pengujian OLTP oleh instance aktif secara bersamaan. Berikut hasil pengujian lienarity database dapat dilihat pada Tabel 6 .

TABEL VI

Hasil PenguJIAN LINEARITY DATABASE

\begin{tabular}{|c|c|c|}
\hline Instance ke & $\begin{array}{c}\text { Openstack } \\
\text { (detik) }\end{array}$ & $\begin{array}{c}\text { Cloudstack } \\
\text { (detik) }\end{array}$ \\
\hline 1 & 154.8445 & 129.2887 \\
\hline 2 & 158.7755 & 129.0991 \\
\hline 3 & 153.7133 & 138.0587 \\
\hline 4 & 161.7316 & 139.3046 \\
\hline 5 & 160.3493 & 140.8554 \\
\hline 6 & 159.5351 & 148.5788 \\
\hline 7 & 159.4898 & 136.8081 \\
\hline 8 & 168.6968 & 154.6885 \\
\hline 9 & 170.7129 & 176.5241 \\
\hline 10 & 176.9130 & 175.0828 \\
\hline
\end{tabular}

Berdasarkan hasil pengujian pada Tabel VI, maka dibuatlah grafik untuk menampilkan hasil visual dari 
pengujian yang telah dilakukan. Adapun grafik tersebut dapat dilihat pada Gambar 10.

\section{Linearity Database}

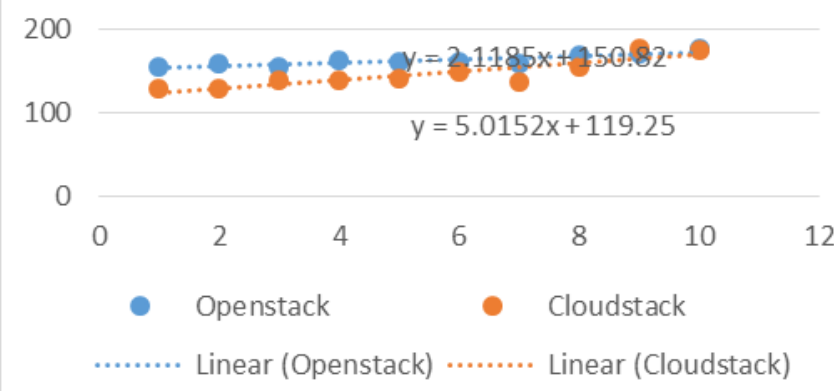

Gambar. 10 Grafik pengujian linearity database

Pengujian database dilakukan untuk mendapatkan waktu eksekusi yang dibutuhkan untuk melakukan beberapa tes OLTP pada database. Beberapa aplikasi seperti online store, inventori barang, aplikasi penjualan serta sistem informasi mengandalkan cache memori untuk menyelesaikan transaksi pada database. Dengan kecepatan transaksi database yang lebih baik maka diharapkan dapat menambahkan, menghapus, mengubah dan menampilkan data dengan lebih baik.

Berdasarkan hasil pengujian overhead database yang dilakukan pada Openstack dan Cloudstack, waktu eksekusi sama sama mengalami kenaikan yang stabil sesuai dengan penambahan jumlah instance yang dijalankan. Pada pengujian ini terlihat bahwa waktu eksekusi oltp database pada instance Cloudstack lebih cepat daripada instance Openstack. Hal tersebut dapat dilihat pada Gambar 9.

Berdasarkan hasil pengujian linearity database yang dilakukan pada Openstack dan Cloudstack, didapatkan hasil bahwa waktu ekselusi mengalami kenaikan sesuai dengan penambahan jumlah instance dan pengujian yang dijalankan. Pada pengujian ini, waktu eksekusi cenderung stabil pada instance Openstack. Sedangkan pada instance Cloudstack, kenaikan waktu eksekusi stabil hingga instance kelima. Instance keenam dan selanjutnya mengalami kenaikan yang cenderung kurang stabil. Pada pengujian linearity database ini, instance pada Cloudstack lebih unggul daripada instance pada Openstack karena waktu eksekusi OLTP database yang lebih rendah. Hal ini dapat dilihat pada Gambar 10.

\section{Hasil dan Analisa Jaringan}

Pengujian jaringan menggunakan Iperf untuk menghitung throughput, jitter dan packet loss. Throughput merupakan salah satu parameter dalam Quality of Service dimana fungsinya untuk melihat perbandingan jumlah data yang di proses kirim dalam waktu pengamatan tertentu [14]. Jitter adalah perbedaan selang waktu kedatangan antar paket di terminal tujuan. Jitter dapat disebabkan oleh terjadinya kongesti, kurangnya kapasitas jaringan, variasi ukuran paket, serta ketidakakuratan paket [15]. Pengujian jaringan menggunakan Iperf sebagai salah satu alat pengujian. Instance Openstack dan Cloudstack menjalankan Iperf server sedangkan client menggunakan PC/Laptop (lihat Gambar 2). Hasil pengujian throughput dapat dilihat pada Tabel 7 berikut.

TABEL VII

Hasil Pengujian OVERHEAD ThroughPut

\begin{tabular}{|c|c|c|c|}
\hline Insance ke & $\begin{array}{c}\text { Openstck } \\
\text { (Mbps) }\end{array}$ & $\begin{array}{c}\text { Cloudsack } \\
\text { (Mbps) }\end{array}$ & $\begin{array}{c}\text { Host } \\
\text { (Mbps) }\end{array}$ \\
\hline 1 & 748 & 723.6 & 764.6 \\
\hline 2 & 750.2 & 732 & 764.6 \\
\hline 3 & 728 & 735 & 764.6 \\
\hline 4 & 710.4 & 762.2 & 764.6 \\
\hline 5 & 744.6 & 769.4 & 764.6 \\
\hline 6 & 750.8 & 741.8 & 764.6 \\
\hline 7 & 731.8 & 762.4 & 764.6 \\
\hline 8 & 771.2 & 783.2 & 764.6 \\
\hline 9 & 777.8 & 781.2 & 764.6 \\
\hline 10 & 785.4 & 782.8 & 764.6 \\
\hline
\end{tabular}

Berdasarkan hasil pengujian pada Tabel VII, dibuatlah grafik untuk menampilkan hasil perbandingan performa Openstack dan Cloudstack pada Gambar 11.

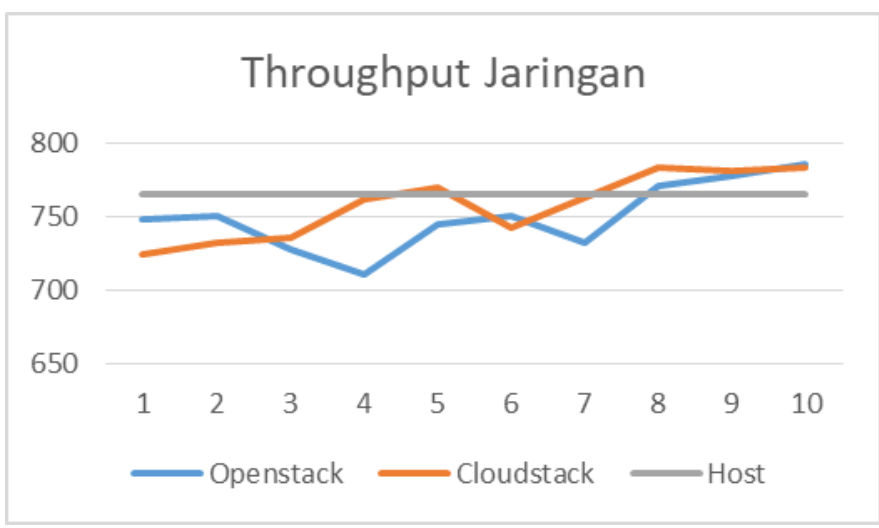

Gambar. 11 Grafik pengujian overhead throughput jaringan

Hasil Pengujian jitter dapat dilihat pada Tabel 8 berikut ini.

TABEL VIII

HASIL PENGUJIAN OVERHEAD JITTER

\begin{tabular}{|c|c|c|c|}
\hline Instance ke & $\begin{array}{c}\text { Openstack } \\
(\mathbf{m s})\end{array}$ & $\begin{array}{c}\text { Cloudstack } \\
(\mathbf{m s})\end{array}$ & $\begin{array}{c}\text { Host } \\
(\mathbf{m s})\end{array}$ \\
\hline 1 & 0.0608 & 0.0542 & 0.0322 \\
\hline 2 & 0.087 & 0.0414 & 0.0322 \\
\hline 3 & 0.0808 & 0.0505 & 0.0322 \\
\hline 4 & 0.0666 & 0.056 & 0.0322 \\
\hline 5 & 0.076 & 0.0532 & 0.0322 \\
\hline 6 & 0.0638 & 0.0558 & 0.0322 \\
\hline 7 & 0.058 & 0.0566 & 0.0322 \\
\hline 8 & 0.0638 & 0.0766 & 0.0322 \\
\hline 9 & 0.0622 & 0.0542 & 0.0322 \\
\hline 10 & 0.06175 & 0.0666 & 0.0322 \\
\hline
\end{tabular}

Berdasarkan hasil pengujian pada Tabel VIII, dibuatlah grafik untuk menampilkan hasil perbandingan performa Openstack dan Cloudstack dalam bentuk visual pada Gambar 12 berikut. 


\section{Overhead Jitter Jaringan}

0.1

0.05

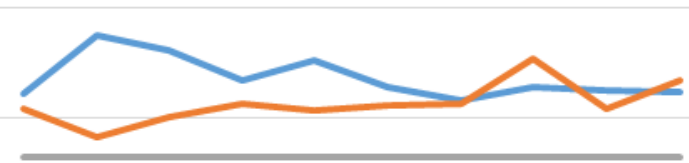

0

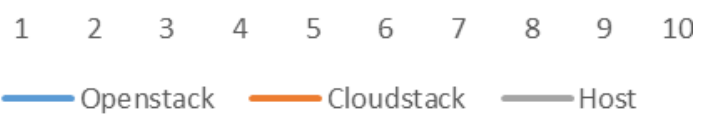

Gambar. 12 Grafik pengujian overhead jitter jaringan

Pada pengujian linearity throughput jaringan, seluruh instance aktif bertugas sebagai Iperf server dan PC menjadi Iperf client. Hasil pengujian linearity throughput dapat dilihat pada Tabel 9 berikut.

TABEL IX

HASIL PENGUJIAN LINEARITY THROUGHPUT

\begin{tabular}{|c|c|c|}
\hline Instance ke & $\begin{array}{c}\text { Openstack } \\
(\mathrm{Mbps})\end{array}$ & $\begin{array}{c}\text { Cloudstack } \\
(\mathrm{Mbps})\end{array}$ \\
\hline 1 & 756.60 & 766.00 \\
\hline 2 & 400.80 & 409.90 \\
\hline 3 & 276.80 & 279.00 \\
\hline 4 & 206.95 & 209.60 \\
\hline 5 & 164.24 & 167.40 \\
\hline 6 & 136.90 & 138.95 \\
\hline 7 & 117.40 & 118.87 \\
\hline 8 & 101.07 & 104.11 \\
\hline 9 & 89.47 & 92.95 \\
\hline 10 & 80.97 & 82.88 \\
\hline
\end{tabular}

Berikut grafik untuk menampilkan hasil visual dari pengujian linearity throughput pada Gambar 13.

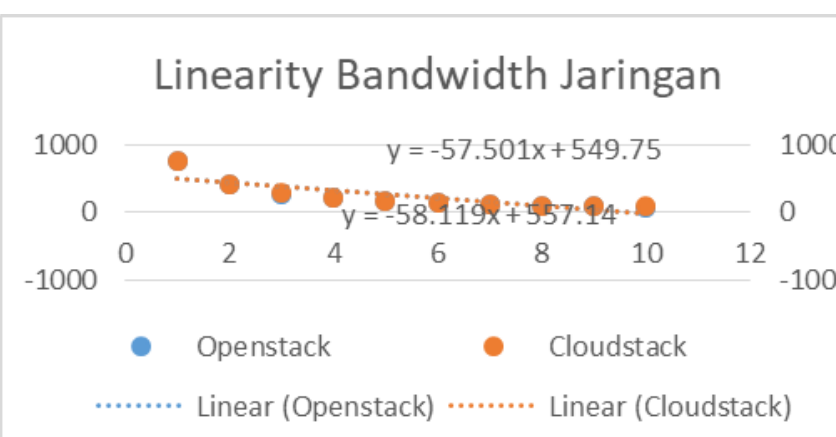

Gambar. 13 Grafik pengujian linearity throughput jaringan

Hasil pengujian dari linearity jitter dapat dilihat pada Tabel 10 berikut ini.

TABEL $X$

HASIL PENGUJIAN LINEARITY THROUGHPUT

\begin{tabular}{|c|c|c|}
\hline Instance ke & $\begin{array}{c}\text { Openstack } \\
(\mathrm{ms})\end{array}$ & $\begin{array}{c}\text { Cloudstack } \\
(\mathrm{ms})\end{array}$ \\
\hline
\end{tabular}

\begin{tabular}{|c|c|c|}
\hline 1 & 756.60 & 766.00 \\
\hline 2 & 400.80 & 409.90 \\
\hline 3 & 276.80 & 279.00 \\
\hline 4 & 206.95 & 209.60 \\
\hline 5 & 164.24 & 167.40 \\
\hline 6 & 136.90 & 138.95 \\
\hline 7 & 117.40 & 118.87 \\
\hline 8 & 101.07 & 104.11 \\
\hline 9 & 89.47 & 92.95 \\
\hline 10 & 80.97 & 82.88 \\
\hline
\end{tabular}

Tampilan visual dari hasil pengujian linearity jitter dapat dilihat pada Gambar 14 berikut ini.

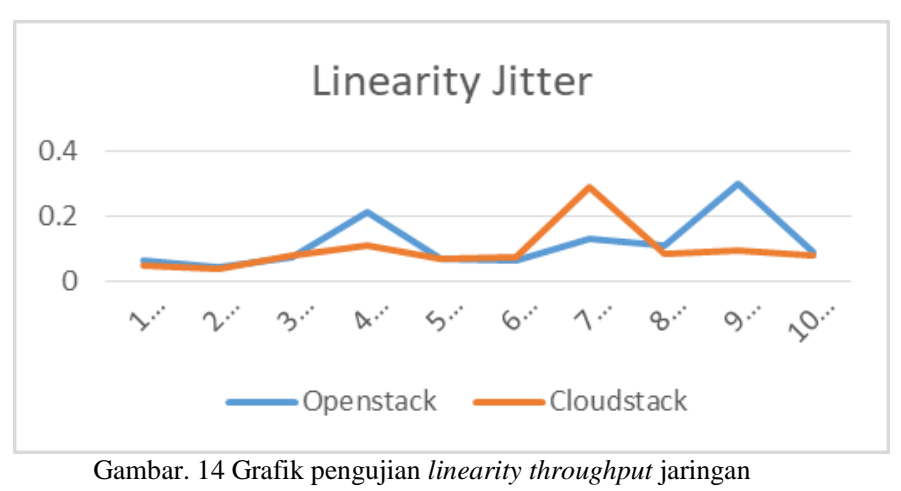

Gambar. 14 Grafik pengujian linearity throughput jaringan

Pengujian pada jaringan private bertujuan untuk mendapatkan kecepatan throughput, variasi delay atau jitter dan persentase packet loss dalam suatu lingkungan internal kerja yang berada dalam satu gedung atau satu ruangan. Beberapa layanan seperti ftp dan rdp memerlukan throughput yang tinggi serta jitter dan packet loss yang rendah. Throughput merupakan kecepatan aktual dari pengiriman data, jitter bertanggung jawab pada kondisi kestabilan jaringan sedangkan packet loss mengarah pada data yang gagal sampai ke tempat tujuan. Iperf menggunakan protokol TCP untuk menghitung throughput serta protokol UDP untuk menghitung jitter dan packet loss.

Berdasarkan hasil pengujian overhead throughput jaringan pada Openstack dan Cloudstack, kenaikan dan penurunan kecepatan cenderung tidak stabil. Pada pengujian yang telah dilakukan, tidak diberikan limitasi bandwidth. Hal ini dimaksudkan agar throughput jaringan melalui protokol TCP dapat mencapai nilai kecepatan maksimal sesuai dengan batasan kemampuan mesin yang digunakan. Pada Openstack kecepatan throughput instance berkisar antara 710,4 Mbps hingga 785,4 Mbps dengan kecepatan rata rata 749.82 Mbps . Pada Cloudstack kecepatan throughput instance berkisar antara antara 723,6 Mbps hingga 783,2 Mbps dengan kecepatan rata rata $757.36 \mathrm{Mbps}$. Berdasarkan grafik pada Gambar 12, hasil pengujian jitter pada Cloudstack relatif lebih rendah dibandingkan dengan Openstack. Pengujian overhead pada Openstack dan Cloudstack pada jaringan private tidak mengalami packet loss untuk tiap tiap hasil pengujian.

Berdasarkan hasil pengujian linearity throughput jaringan yang dilakukan pada Openstack dan Cloudstack, didapatkan bawah kecepatan transfer mengalami 
penurunan sesuai dengan penambahan jumlah instance dan beban pengujian yang dijalankan. Pada pengujian ini, throughput pada Openstack dan Cloudstack relatif sama. Hal ini dapat dilihat pada Gambar 13. Pada Pengujian jaringan menggunakan protokol UDP pada Openstack dan Cloudstack, didapatkan hasil bahwa jitter jaringan mengalami kenaikan dan penurunan yang kurang stabil. Hal ini dapat dilihat pada Gambar 14. Sedangkan untuk packet loss, persentasi paket yang hilang tetap sebesar $0 \%$.

\section{KESIMPULAN}

Berdasarkan hasil pengujian dan analisa terhadap performa Openstack dan Cloudstack dalam aspek webserver, komputasi, database dan jaringan, maka dapat diambil kesimpulan sebagai berikut.

1. Instance pada Openstack unggul dalam aspek pengujian komputasi dan weserver, sehinga pada penggunaan yang berfokus pada pengembangan aplikasi berbasis web ataupun yang memerlukan daya komputasi yang lebih tinggi disarankan untuk menggunakan Openstack.

2. Instance pada Cloudstack unggul dalam aspek pengujian database dan jaringan. Cloudstack unggul pada throughput jaringan private dan publik. Sedangkan untuk jitter dan packet loss, pengujian pada instance Cloudstack relatif lebih rendah dibandingkan Openstack. Pada pengujian database, waktu eksekusi pada Cloudstack lebih baik daripada Openstack.

\section{REFERENSI}

[1] I. Sofana, Teori dan Praktik Cloud Computing (OpenNebula, VMWare dan Amazon AWS), Bandung: Informatika Bandung, 2012.

[2] M. Ibrahim and Kusnawi, "Analisis dan Implementasi Owncloud Sebagai Media Penyimpanan Pada Yayasan Salman Salman AlFarisi Yogyakarta," Jurnal Ilmiah DASI, vol. 14, no. 04 Desember 2013, pp. 32-37, 2013.

[3] E. Retnaningsih and B. E. Purnama, "Pelacakan Lokasi Hosting Web Perguruan Tinggi Studi Kasus: Perguruan Tinggi Kopertis 6 Jawa Tengah," Seruni FTI UNSA, vol. I, pp. J1-J8, 2012.

[4] Y. Cancer and Z. Alim, "Platform as a Service (PaaS) sebagai layanan sistem operasi cloud computing," Jurnal TIMES, vol. V, no. 1, pp. 32-35, 2016.

[5] T. W. Ananda, Rusmani and A. Mulyana, "Desain dan realisasi sistem grid computing pada infrastructure as a service menggunakan cloud platform Openstack," e-Proceeding of Engineering, vol. 3, no. 1, pp. 743-748, 2016.

[6] M. Fauzan, A. Fiade and F. E. M. A, "Analisis dan perancangan infrastruktur private cloud dengan Openstack," Jurnal Pseudocode, vol. IV, no. 2, pp. 180-189, 2017.

[7] R. Kumar, K. Jain, H. Maharwal, N. Jain and A. Dadhich, "Apache CloudStack: Open Source Infrastructure as a Service Cloud," International Journal of Advancement in Engineering Technology, Management and Applied Science, vol. 1, no. 2, pp. 111-116, 2014.

[8] D. S. Kristian, A. F. Rochim and E. D. Widianto, "Pengembangan Sistem Replikasi dan Redundansi Untuk Meningkatkan Kehandalan Basisdata Mysql," Jurnal Teknologi dan Sistem Komputer, vol. 3 , no. 4, pp. 523-529, 2015

[9] T. A. Gani, A. Arafat and Melinda, "Analisis Kinerja MySQL Cluster Menggunakan Metode Load Balancing," Jurnal Rekayasa Elektrika, vol. 11, no. 4, pp. 129-134, 2015.

[10] Wahyudi and Supini, "Monitoring dan Analisa Traffik Jaringan
Dengan Menggunakan Mikrotik RouterOS," Jurnal Teknologi Informasi, vol. 5, no. 2, pp. 269-276, 2017.

[11] A. Arfriandi, "Perancangan, Implementasi, dan Analisis Kinerja Virtualisasi Server Menggunakan Proxmox, Vmware ESX, dan Openstack," Jurnal Teknologi, vol. 5, no. 2, pp. 182-191, 2012.

[12] P. A. Nugraha, M. A. Irwansyah and H. Priyanto, "Rancang Bangun Web Server Berabsis Linux Dengan Metode Load Balancing (Studi kasus : Laboratorium Teknik Informatika)," Jurnal Sistem dan Teknologi Informasi, vol. 3, no. 1, pp. 1-5, 2016.

[13] Y. Firdaus, S. B. Premapasha and S. Yulias, "Analisis dan Perancangan Sistem Online Transaction Processing (OLTP) Menggunakan SCRUM (Studi Kasus Rumah Sakit Puti Bungsu)," e-Proceeding of Engineering, vol. 4, no. 2, pp. 3130-3137, 2017.

[14] B. Arifwidodo, "Analisis Quality of Service pemanfaatan Ethernet Over IP(EoIP) Tunnel di MikrotikRouterOS dengan Routing Protocol OSPF," Journal of Informatics, Information System, Software Engineering and Applications, vol. 1, no. 1, pp. 1-8, 2018.

[15] Fitri, M. Yamin and L. B. Aksara, "Perbandingan Metode Differentiated Service dengan Metode Integrated Service Untuk Analisa Quality of Service (QoS Video Streaming) Pada Jaringan Multi Protocol Label Switching (MPLS)," semanTIK, vol. 3, no. 1, pp. 135-142, 2017. 